\title{
What does self-medication counseling in Bulgarian community pharmacies look like - a field study
}

\author{
Hristina Lebanova ${ }^{1}$, Stefan Balkanski ${ }^{2}$, Emilia Naseva ${ }^{3}$, Ilko N. Getov ${ }^{3}$ \\ 1 Faculty of Pharmacy, Medical University - Pleven, Pleven, Bulgaria \\ 2 Bulgarian Pharmaceutical Union, Sofia, Bulgaria \\ 3 Medical University of Sofia, Sofia, Bulgaria \\ Corresponding author: Hristina Lebanova (hristina.lebanova@gmail.com)
}

Received 26 August 2020 • Accepted 11 October 2020 • Published 3 November 2020

Citation: Lebanova H, Balkanski S, Naseva E, Getov IN (2020) What does self-medication counseling in Bulgarian community pharmacies look like - a field study. Pharmacia 67(4): 289-293. https://doi.org/10.3897/pharmacia.67.e57752

\begin{abstract}
The aim of the study is to identify the current practices of self-medication in Bulgaria, estimate the extent patients are influenced by information about the safety of OTC products and pharmacists' role and behavior in the process. An anonymous, questionnaire-based, descriptive study was carried out among 280 pharmacists.

The majority of the patients (92.6\%) ask for pharmacists' advice before buying OTC products. Most often patients need OTC drugs for mild conditions (80.7\%), to save time (63.9\%), and because they are unable to consult a physician (61.9\%). The medium duration of consultation for an OTC product is between 5 and 10 minutes. The main barriers hindering the process are unwillingness from the patient (72.5\%), lack of time (27.5\%), and lack of confidentiality (26.6\%). OTC medicines are considered safer than prescription-only medicines by pharmacists.
\end{abstract}

Pharmacists could substantially contribute to rational self-medication and alleviate the burden on healthcare systems.

\section{Keywords}

self-medication, pharmaceutical counseling, over-the-counter medicines

\section{Introduction}

Self-medication is defined as the selection and use of medicines by individuals to treat self-recognized or self-diagnosed conditions or symptoms (WHO 2000). The role of self-medication in modern healthcare systems is increasing as healthcare policies worldwide promote citizens' empowerment and responsibility concerning their health and well-being (Bonsignore et al. 2014). It is a common practice among many people around the world (Irfadh et al. 2013).
Previous local studies indicate that the consumption of OTC products is increasing and the main stimulus for patients is convenience (Tsvetkova et al. 2014; Belcheva et al. 2016; Belcheva et al. 2017). 9.7 billion packs of non-prescription medicines were bought by Europeans in 2019 (AESGP 2019). In total, more than 200 active pharmaceutical ingredients (by INN) in more than 4000 different medicinal products are available in Europe without prescription. These include medicines for common ailments such as allergies, stomach upsets, cuts, bites \& rashes, coughs \& cold, pain. The general benefits of self-medication include 
facilitating better use of clinical skills, increasing access to medication, and contributing to reducing prescribed drug costs associated with publicly funded health programs (Hughes et al. 2001; Noone and Blanchette 2018). However, self-medication is associated with risks such as misdiagnosis, use of excessive drug dosage, prolonged duration of use, drug interactions, and polypharmacy (Hughes et al. 2001). The inappropriate use of products for self-medication results also in adverse drug reactions, disease masking, increased morbidity, antibiotic resistance, and wastage of healthcare resources (Awad et al. 2006; James et al. 2006; Sahebi and Vahidi 2009; Suleman et al. 2009; Alam et al. 2015; Dyar et al. 2019).

In Bulgaria over-the-counter (OTC) medicines are dispensed without prescription and are sold exclusively in community pharmacies (ZLPHM 2019). Pharmacists are considered the most accessible healthcare professionals in Bulgaria. They can recommend OTC medicines but also provide overall pharmaceutical care (ZLPHM 2019; Georgiev 2018). In 1992, FIP developed standards for pharmacy services entitled "Good Pharmacy Practice (GPP) in community and hospital pharmacy settings". One of the four pharmacy elements of good pharmacy practice covers activities associated with self-care, including advice for managing ailments that can be self-treated successfully (WHO 2000).

However numerous studies suggest that the quality of primary health care in self-medication would improve if pharmacists' involvement were more intense (Krishnan and Schaefer 2000; You et al. 2011). The role of the pharmacist in promoting rationale self-medication is crucial in improving patient outcomes. To elevate the quality of counseling it is important to identify everyday practice and unmet needs.

\section{Aim}

The aim of this study is to identify the current practices of self-medication in Bulgaria, estimate the extent patients are influenced by information about the safety of OTC products, and pharmacists' role and behavior in this process.

\section{Materials and methods}

An anonymous, questionnaire-based, descriptive study was performed in 2019. The questionnaire was developed based on a pilot study conducted in Bulgaria in 2018 (Lebanova et al. 2018). It consisted of a total of 16 questions divided into 2 sections: (1) patients' habits and preferences in over-the-counter medications and (2) role and behavior of the pharmacist in patient self-medication counseling. All questions were with multiple-choice answers and provided an opportunity for an open-ended response.

Data were analyzed using SPSS. Descriptive statistics were reported by mean or percentage, as appropriate.

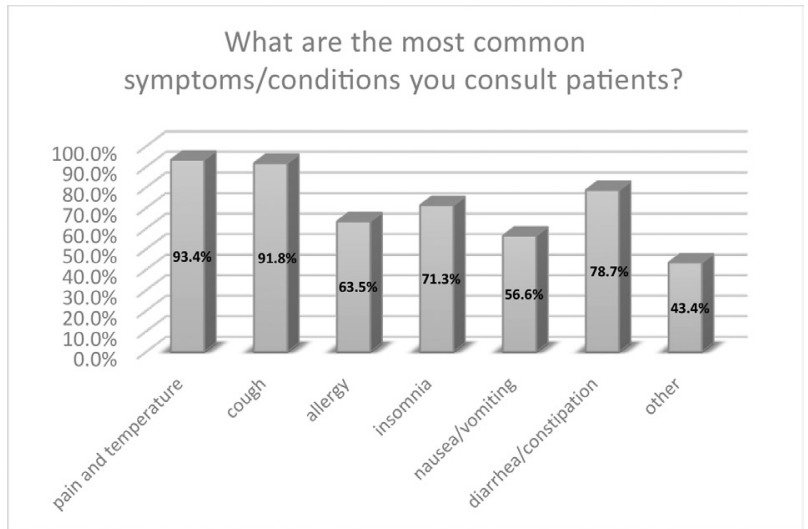

Figure 1. Most common symptoms/conditions for which patients seek advice from the pharmacist.

The category variables were presented as absolute and relative frequencies, and the quantitative ones - as median and interquartile range, as they are not normally distributed. The Kolmogorov-Smirnov method was used to estimate the shape of the distribution. The relationships between categorical variables were evaluated by chi-square analysis (Fisher's exact test in tables $2 \times 2$ ). The Spearman correlation coefficient was used to estimate the relationship between quantitative variables. Statistical analyzes were applied at a significance level of 0.05 .

\section{Results \\ Characteristics of the respondents}

A total of 500 questionnaires were distributed among a simple random sample of community pharmacists for one month in 2019. 280 participants completed the survey (response rate 56\%). There were 204 (84.6\%) female respondents; the average age was 44 years old.

A total of 241 valid questionnaires were collected and analyzed. Respondents' average work experience was 19.9 years (min 0.5-max 57).

\section{Patients' practices and preferences in over-the-counter medications}

Respondents reported that the majority of the patients (92.6\%) ask for pharmacists' advice before buying an overthe-counter product. Most often patients need OTC drugs for mild and transient conditions $(80.7 \%)$, to save time (63.9\%) and because they are unable to consult a physician at the moment (61.9\%). According to pharmacists, a quarter of patients $(26.6 \%)$ need OTC medicines for urgent conditions. Pharmacists with the longest work experience (more than 20 years) consider an urgent condition and easy access as patients' main reasons to self-medicate $(\mathrm{p}<0.05)$. The most common symptoms presented at the time of the consultation are pain and temperature (93.4\%), cough (91.8\%), diarrhea/constipation (78.9\%), and insomnia (71.3\%) (Fig. 1). 


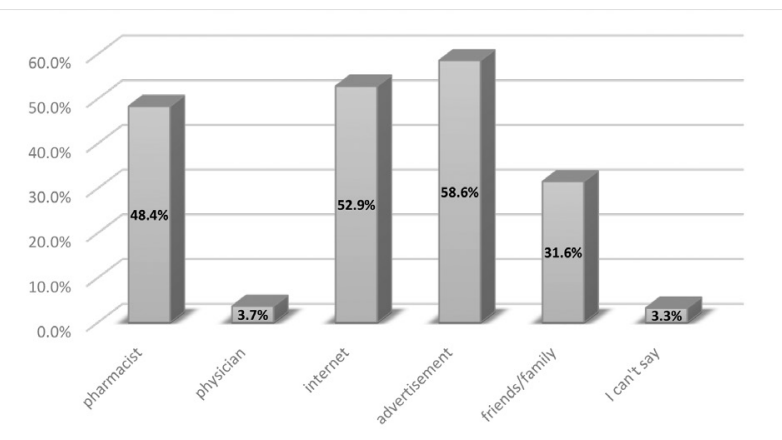

Figure 2. Patients'sources of information according to the respondents.

According to the pharmacists' experience, a quarter of the patients rarely or never $(27.6 \%)$ inquire about the risks or possible adverse reactions of the OTC medicines they use or about possible drug interactions (26.2\%). Those who want to purchase OTC products for pain and temperature $(\mathrm{p}<0.05)$, nausea and vomiting $(\mathrm{p}<0.05)$, diarrhea/constipation $(\mathrm{p}=0.055)$, and cough $(\mathrm{p}<0.1)$ are most interested in the safety profile of the drugs and the possible ADRs.

However, patients' decision could be swayed by providing information on potential ADRs in the majority of cases $(90.4 \%)$. The majority of the participants in the study $(73.5 \%)$ consider that patients do not rationally use OTC medicines. Patients' main sources of information are advertisement (58.6\%), internet (52.9\%) and pharmacists (48.4\%) (Fig. 2).

The majority of the pharmacists participating in the study (64.6\%) believe that providing additional information about the benefits and the risk associated with a specific OTC product could change patients' decision about the purchase.

\section{Role and behavior of the pharmacist in patient self-medication}

$53 \%$ of the respondents state that the medium duration of consultation for an OTC product is between 5 and 10 minutes and less than 5 minutes for $44 \%$. There is a correlation between the nature of the presented symptoms and the duration of the consultation; the longest ones are in the pain/temperature domain $(\mathrm{p}<0.05)$.

The majority of the respondents estimate their confidence in providing consultation in self-medication as high (44.9\%) and very high $(32.2 \%)$. The main factors hindering the process are the unwillingness from the patient $(72.5 \%)$, lack of time $(27.5 \%)$, and lack of confidentiality in the pharmacy environment and premises (26.6\%) (Fig. 3). Patients' unwillingness is the main factor among the younger pharmacists with less than 10 years of work experience $(\mathrm{p}<0.05)$.

Pharmacists also consider OTC medicines safer $(51.6 \%)$ but with a greater potential for abuse $(49.25 \%)$ than prescription-only medicines (POM). Some of them also believe that OTC products are less effective (25\%) and with more potential for drug-drug interactions (16.4\%) and adverse drug reactions (13.1\%). $90.4 \%$ of the respondents state that the safety profile of an OTC medicine

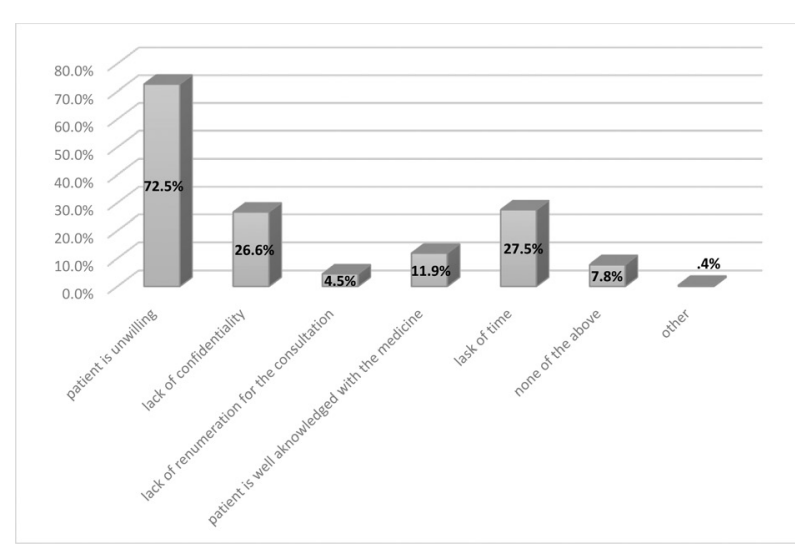

Figure 3. Main factors that could prevent pharmacists from providing consultation.

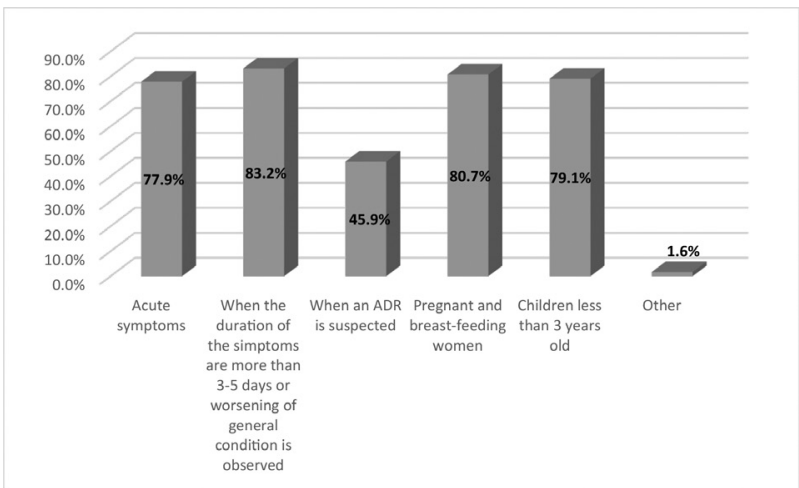

Figure 4. Pharmacists'reasons to refer patient to physician.

is of the utmost importance when they recommend it to patients. One third (29.9\%) of the participants claim that they always provide safety information to the patients and this is especially visible in the group with the longest work experience ( $p<0.05)$. The main reasons to recommend consultation with physicians are presented in Fig. 4.

\section{Discussion}

General practitioners (GPs) are the primary source for treating minor ailments (EPPOSI 2013). The majority of these conditions could be managed successfully in a pharmacy setting. Improving self-care and promoting rational self-medication can help to ease the burden on the healthcare systems especially in the context of the Covid-19 pandemic. Minor ailments such as pain, temperature, cough, diarrhea/constipation, allergy are in most cases widespread seasonal conditions. One of the first steps in ascertaining the role of the pharmacist as an accessible healthcare resource capable of meeting the challenges of the evolving consumer needs is the recognition of pharmacists' ability of counseling and providing pharmaceutical care in self-medication. The quality of counseling depends on many factors but according to our results, the main barrier is the patient's unwillingness. This is indicative that there is still an unmet need in recognising the pharmacists' role as healthcare consultants and sources of reliable health information. 
Another barrier to adequate counseling is patients' perception of the pharmacist's role. The community-based practice has evolved from compounding and dispensing to pharmaceutical care and counseling (Goode et al. 2019). The results of our study show that Bulgarian consumers haven't embraced the change as the primary sources of information for the patients are still advertisements and the internet. The quality of medicines information on the world-wide-web is known to be mostly mediocre and could lead to drug-related problems (Lebanova et al. 2014). To facilitate counseling and promote safe self-medication pharmacists should lead the process. As the control of a disease is a bilateral process between the patient and the physician, self-care is a bilateral process between the patient and the pharmacist (Stoev et al. 2015).

Pharmacists' attitude toward OTC medicines is crucial in shaping their behavior in self-medication counseling. Our study found that Bulgarian pharmacists believe that OTC products are safe. However, OTCs are believed also to be of a higher potential for abuse, drug interactions, and ADRs. It is not accidental that the majority of pharmacists emphasize on safety when counseling along with efficacy. This phenomenon is most visible among those with the longest work experience. Promoting rational drug and adherence use is of utmost importance in reducing the risk of self-medication (You et al. 2011). One of the most vulnerable populations are patients with chronic diseases who are prone to a higher risk of drug interactions between prescription drugs for chronic diseases and OTC products (Kaufman et al. 2002).

The results of our study suggest that Bulgarian pharmacists can undertake a more active role in patients' self-care. Published data shows that community pharmacist-provided self-care programs had demonstrated a positive impact on chronic diseases (Barbanel 2003; Doucette et al. 2009).

\section{Conclusion}

Self-care and self-medication are an important aspect of the evolving healthcare systems. Pharmacists play a crucial role in empowering patients to manage minor ailments. The results of our study show that pharmacists are willing to provide counseling and participate in the process. The behavior of the pharmacists is shaped mainly by their belief that OTC medicines are effective but with higher potential for abuse, drug interactions, and ADRs. The main barrier to this process is patients' perception of the role of the pharmacist as a health consultant.

\section{Acknowledgements}

The authors thank the Bulgarian Pharmaceutical Union and CPD accreditation Commission for the support in distributing the questionnaires.

\section{References}

AESGP (2019) Evolving the self-care environment. https://aesgp.eu/content/uploads/2020/05/AESGP_ActivityReport2019-interactive.pdf [August 19, 2020]

Alam N, Saffoon N, Uddin R (2015) Self-medication among medical and pharmacy students in Bangladesh. BMC Research Notes 8: e763. https://doi.org/10.1186/s13104-015-1737-0

Awad AI, Eltayeb IB, Capps PA (2006) Self-medication practices in Khartoum State, Sudan. European Journal of Clinical Pharmacology 62: 317-324. https://doi.org/10.1007/s00228-006-0107-1

Barbanel D (2003) Can a self-management programme delivered by a community pharmacist improve asthma control? A randomised trial. Thorax 58: 851-854. https://doi.org/10.1136/thorax.58.10.851

Belcheva V, Grigorov E (2016) Patients' knowledge about the "Rx-toOTC" switch process in Bulgaria. Scripta Scientifica Pharmaceutica 3: 39-39. http://journals.mu-varna.bg/index.php/ssp/article/view/2456

Belcheva V, Naseva E, Grigorov E, Zlatanova T (2017) Study of Bulgarian patient's awareness on the process of medicines reclassification in terms of drug safety and effectiveness /part I/. Health Policy and Management 17: 18-20.

Bonsignore C, Brolis E, Ionescu A, Karusinova V (2014) Patient Empowerment and Centredness - European Health Parliament.

Doucette WR, Witry MJ, Farris KB, McDonough RP (2009) Community pharmacist - provided extended diabetes care. Annals of Pharmacotherapy 43(5): 882-889. https://doi.org/10.1345/aph.1L605
Dyar OJ, Beović B, Pulcini C, Tacconelli E, Hulscher M, Cookson B, Ashiru-Oredope D, Barcs I, Blix HS, Buyle F, Chowers M, Čižman M, Del Pozo JL, Deptula A, Dumpis U, Florea D, van de Garde E, Geffen Y, Giske CG, Grau S, Hajdú E, Hell M, Hondo, Hussein K, Huttner B, Kern W, Kernéis S, Knepper V, Kofteridis D, Kostyanev T, Kuijper E, Lebanova H, Lewis R, Cordina CM, Matulionyte R, Maurer F, Messiaen P, Miciuleviciene J, Mrhar A, Nabuurs-Franssen M, Naesens R, Oxacelay C, Pagani L, Paño-Pardo JR, Paul M, Petrikkos G, Pluess-Suard C, Popescu GA, Porsche U, Prins J, Rello J, Rodríguez-Baño J, Rossolini GM, Salzberger B, Seme K, Simonsen GS, Sînziana M, Skovgaard S, Smith I, Sönsken U, Soriano A, Sviestiņa I, Szilagyi E, Tängdén T, Tattevin P, Tsioutis C, Vilde A, Wanke-Rytt M, Wechsler-Fördös A, Zarb P (2019) ESCMID generic competencies in antimicrobial prescribing and stewardship: towards a European consensus. Clinical Microbiology and Infection 25: 13-19. https://doi.org/10.1016/j.cmi.2018.09.022 EPPOSI (2013) Consumer Perceptions of Self Care in Europe Quantitative Study 20132 EPPOSI self care barometer: quantitative study perceptions of self care in Europe.

Georgiev S (2018) Self-management - key aspect of pharmaceutical care. $2^{\text {nd }}$ ed. Tea Design, Sofia.

Goode J-V, Owen J, Page A, Gatewood S (2019) Community-Based Pharmacy Practice Innovation and the Role of the Community-Based Pharmacist Practitioner in the United States. Pharmacy 7(3): e106. https://doi.org/10.3390/pharmacy7030106 
Hughes CM, McElnay JC, Fleming GF (2001) Benefits and risks of self medication. Drug Safety 24: 1027-1037. https://doi. org/10.2165/00002018-200124140-00002

Irfadh M, Azhar M, Gunasekaran K, Kadirvelu A, Gurtu S, Sadasivan S, Kshatriya BM (2013) 5 International Journal of Collaborative Research on Internal Medicine \& Public Health Self-medication: Awareness and Attitude among Malaysian Urban Population.

James H, Handu SS, Al Khaja KAJ, Otoom S, Sequeira RP (2006) Evaluation of the Knowledge, Attitude and Practice of Self-Medication among First-Year Medical Students. Medical Principles and Practice 15: 270-275. https://doi.org/10.1159/000092989

Kaufman DW, Kelly JP, Rosenberg L, Anderson TE, Mitchell AA (2002) Recent patterns of medication use in the ambulatory adult population of the United States: The Slone survey. Journal of the American Medical Association 287: 337-344. https://doi.org/10.1001/jama.287.3.337

Krishnan HS, Schaefer M (2000) Evaluation of the impact of pharmacist's advice giving on the outcomes of self-medication in patients suffering from dyspepsia. Pharmacy World and Science 22: 102-108. https://doi.org/10.1023/A:1008733207854

Lebanova H, Getov I, Grigorov E (2014) Practical tool to assess reliability of web-based medicines information. Medicinski Glasnik 11: 221-227.

Lebanova HV, Staynova R, Getova V (2018) Pharmacists' role in risk communication on self-medication: Pilot study from Bulgaria. In: $18^{\text {th }}$ ISoP Annual Meeting "Pharmacovigilance without borders". Drug Safety 41: 1103-1273. [ISoP18-1227] https://doi.org/10.1007/ s40264-018-0719-2
Noone J, Blanchette CM (2018) The value of self-medication: summary of existing evidence. Journal of Medical Economics 21: 201-211. https://doi.org/10.1080/13696998.2017.1390473

Sahebi L, Vahidi R (2009) Self-Medication and Storage of Drugs at Home Among the Clients of Drugstores in Tabriz. Current Drug Safety 4: 107-112. https://doi.org/10.2174/157488609788172982

Stoev S, Atanasov V, Getov I (2015) The role of patients and medical specialists in achieving higher level of therapy compliance - an example with willingness to participate in clinical trials. CBU International Conference Proceedings 4: 767-772. https://doi.org/10.12955/cbup.v4.847

Suleman S, Ketsela A, Mekonnen Z (2009) Assessment of self-medication practices in Assendabo town, Jimma zone, southwestern Ethiopia. Research in Social and Administrative Pharmacy 5: 76-81. https://doi.org/10.1016/j.sapharm.2008.04.002

Tsvetkova A, Todorova A, Petkova V, Management P (2014) The role of pharmacist as an advisor on responsible self-medication: a survey. World J of Pharmacy and Pharmaceutical Sciences 3: 325-335.

WHO (2000) Guidelines for the Regulatory Assessment of Medicinal Products for use in Self-Medication. https://apps.who.int/iris/bitstream/handle/10665/66154/WHO_EDM_QSM_00.1_eng.pdf [August 18, 2020]

You JH, Wong FY, Chan FW, Wong EL, Yeoh E kiong (2011) Public perception on the role of community pharmacists in self-medication and self-care in Hong Kong. BMC Clinical Pharmacology 11: e19. https://doi.org/10.1186/1472-6904-11-19

ZLPHM (2019) Medicinal Products in Human Medicine Act. 